\title{
Correspondence
}

British Heart fournal, 1974, 36, 391.

\section{Truncus solitarius pulmonalis}

Sir:

May I comment on the title of the interesting case report by Allwork and Bentall (British Heart fournal, 35, 977). The authors may be correct in stating that only I5 cases of 'truncus solitarius pulmonalis' have been reported, but the underlying abnormality, namely aortic valve atresia, is probably the commonest cause of stillbirth or neonatal death - I have studied scores of examples and so have many pathologists working for coroners.

I am in favour of preserving classical descriptions but not if it leads to this sort of false impression, which may spark off more reports of a very common condition.

Unequal division of the truncus arteriosus by the spiral septum may cause aortic atresia with a large pulmonary trunk (as in this example); or pulmonary atresia with a large aorta. It would be just as accurate to refer to this latter as 'truncus solitarius aorticus', though pulmonary atresia is so common.

In aortic valve atresia, the hypoplastic ascending aorta joins the arch at the large ductus, and it gives origin to the coronary arteries at its proximal end, though these may be minute, anomalous in distribution, and pretty useless since they convey a tiny stream of mixed venous blood retrogradely from the ductus.

\section{R. E. B. Hudson, Shoreham-by-Sea, Sussex.}

1. This letter was shown to the authors who comment as follows.

Sir:

To the best of our knowledge only is cases have been reported which exhibited precisely the anatomy we described, namely a single (right) ventricle, a

solitary atrioventricular valve, agenesis of the left ventricle and mitral valve, aortic valve atresia, and retrograde coronary circulation through an atretic aorta, via the ductus arteriosus.

With respect to the incidence, Nadas' series of IOI cases of the hypoplastic left heart syndrome included only 2 cases with aortic and mitral atresia; these observations, however, indicated the presence of two ventricles. Both Abbott, in her classic series, and Keith, Rowe, and Vlad quoted the incidence of aortic atresia to be $\mathrm{I} \cdot 2$ per cent of necropsies in infants with congenital heart disease, though the latter authors indicated that it was probably a more frequent cause of death from congenital heart disease in the first month of life.

However, truncus solitarius pulmonalis should perhaps be regarded as the most extreme form of the hypoplastic left heart syndrome. It is recognizable by this term, but we do not wish to imply that all forms of aortic atresia should be described in this way.

\author{
S. P. Allwork, \\ Department of Surgery, \\ Division of Cardiovascular Disease, \\ Royal Postgraduate Medical School, \\ Hammersmith Hospital, \\ London WI2. \\ R. H. C. Bentall, \\ Department of Surgery, \\ Queen Mary's Hospital for Children, \\ Carshalton, Surrey.
}

\section{References}

Abbott, M. E. (1936). Atlas of Congenital Cardiac Disease. American Heart Association, New York.

Keith, J. D., Rowe, R. D., and Vlad, P. (1967). Heart Disease in Infancy and Childhood. Macmillan, New York.

Nadas, A. (1966). Pediatric Cardiology. W. B. Saunders, Philadelphia. 